\title{
Research on Coordination of Agricultural Cooperatives and Supermarkets Supply Chain Based on Option Contract at the Background of VMI Model
}

\author{
Zhenlai You* and Botao Zhao
}

School of Economics and Management; Yanshan University, 066004, Qinhuandao, China

\begin{abstract}
This paper introduces vendor managed inventory model into agricultural product supply chain which the agricultural cooperatives and supermarkets are directly connected with and achieves coordination by option contract. We find that the expected profit and the optimal order quantity of supply chain under decentralized decision-making situation are less than the levels of centralized decision-making situation and there's double marginalization in this system. Our research demonstrates that option contract can coordinate the agricultural cooperatives and supermarkets and achieve a reasonable distribution of profits between them.
\end{abstract}

Keywords: Supply chain, option contract, vendor managed inventory, Stackelberg game.

\section{INTRODUCTION}

Vendor managed inventory (VMI) was first proposed by Magee in 1958 (Daozhi Zhao, 2012) [1], then obtaining a great deal of research attention, especially after the brilliant achievements made by Procter \& Gamble and Wal-Mart. Owing to sharing information with each other, upstream suppliers can monitor the terminal market demand timely, so as to avoid the bullwhip effect caused by information distortion in the process of transmission. Meanwhile downstream retailers can pay more attention to their core businesses, economizing on the manpower, materials and wealth resources for inventory management.

Comparing the expected performance of the VMI supply chain with a traditional "serially linked" supply chain, S.M. Disney et al. (2003)[2] found that the former could effectively cope with volatile changes in demand caused by discounted ordering or price variations. Liu et al. (2003) [3] presented three models according to time-based, quantity-based and time-and-quantity dispatch policy for coordinating inventory and delivery decision in VMI systems. Tang et al. (2005)[4] proved that either supplier or retailer made decision first in the game, the performance of supply chain would get improved distinctly, contrasting with the result under simultaneous decision-making. Liang et al. (2006)[5] considered two-echelon VMI supply chain for probability research analysis, making decisions for supplier whether to accept the VMI strategy led by retailer and how to make the best delivery strategy. Bichescu et al. (2009)[6] established three different models for VMI supply chain, in which the process of decision making was led separately by supplier, retailer and both of them when they were neck and neck. They showed that VMI could result in cost reduction and optimization of the supply chain. Yu et al. (2009)[7] used Stackelberg game to work out the problem how enterprises in the supply chain work together to maximize their profits based on VMI supply chain.

However, it can't achieve the coordination of supply chain only through VMI, there will be double marginalization effect in it. Zhao et al. (2012)[1] studied a great deal of domestic and oversea research literatures of recent years, pointing out the VMI model was only good for downstream members, and the whole system was far away from Pareto equilibrium. In order to achieve the coordination of supply chain, researchers have put forward varieties of supply chain contracts, including wholesale price contract, buyback contract, revenue sharing contract, quantity flexibility contract, etc. Subsequently, option contract as a financial tool was introduced into the study of supply chain coordination in recent years.

Sarmah et al. (2007)[8] developed a coordination mechanism through credit option such that both the parties can divide the surplus equitably after satisfying their own profit targets. Sarmah S et al. (2008)[9] proposed a model containing one supplier and multiple retailers with credit option. Padilla et al. (2009)[10] developed two models, considering multiple suppliers and one retailer, and one supplier and one retailer. The former utilized the hybrid model with wholesale price contract, buyback contracts and option contract; while the latter only used the option contract. Via simulation analysis, they drew a conclusion that option contract was more suitable for supply chain coordination. Chaharsooghi et al. (2010)[11] proposed an incentive scheme for sharing the benefits between buyer and supplier in terms of credit option. Meanwhile, it indicated that the coordination of the reorder point, together with order quantity, could increase the overall chain profitability as well as each member's profitability. With the benchmark based on the wholesale price 
mechanism, Zhao et al. (2010)[12] showed that option contract could coordinate the supply chain and fulfill Pareto improvement. Wu et al. (2011)[13] studied the coordination of VMI supply chain under uncertain demand via option contract, the higher the level of uncertainty, the more important the option contract was. It supplied suppliers a greater proportion of profits and retailers less risk of shortage rather than simply increasing profits. Li et al. (2012)[14] assumed that both market demand and retail price are random variables. In other words, when demand is inadequate, the price will fall down, otherwise the price will rise up. In this case, they design an option contract to achieve supply chain coordination with or without credit default. Du et al. (2013)[15] studied the coordination of two-echelon supply chains using a credit payment option and a wholesale price discount offer. With impartial profit sharing, such a policy can be beneficial for both the parties towards increasing total supply chain profitability.

Many researchers regard supplier as the leader in option contract literatures, however Cai et al. $(2011,2012)[16,17]$ pointed out that retail giants such as Wal-Mart and Carrefour, are often in a position of leadership in the supply chain, while supplier is a follower. They developed a model of supply chain led by retailer, and coordinated through option contract. The most significant function of introducing the option contract is to confront with market demand fluctuation, and enhance the ability of individual members against the demand uncertainty and share risk with each other.

With the rapid development of modern agriculture and close attention to food safety, agricultural products supply chain is facing great challenge. In 2008, the Commerce Department and the Ministry of Agriculture jointly issued the notice of connecting agriculture with supermarkets, leading large supermarkets and professional cooperatives to joint directly. This model effectively shortens the transportation process of fresh agricultural products from fields to consumers' hands, reducing the loss of goods in circulation process. By the end of 2011, China has more than 15,600 agricultural cooperatives connecting with chain operation enterprises in which supermarkets occupy the majority.

Zhao et al. (2009)[18] proposed revenue sharing contract model to coordinate agricultural product supply chain. Moustiera et al. (2010)[19] studied the role farmer organizations played to promote small-scale farmers getting more market opportunities from supermarket, especially ensuring food quality that consumers increasingly focus on. Li et al. (2011)[20] had carried on the empirical research on factors influencing professional cooperative to operate the model of connecting agriculture with supermarkets. Liu et al. (2012)[21] found that the quality and safety of agricultural products are mainly decided by the suppliers' behavior through investigation. Ye et al. (2011)[22] developed the "company + farmer" contract-farming supply chain model and coordinated it.

On the basis of the former research, this paper introduces the VMI into two-echelon supply chains with agricultural cooperative and supermarket, achieving supply chain coordination through option contract. In our country, large supermarkets are often in a leadership position relying on capital strength, market information and channel power, while cooperatives become followers. So we assume the supermarket has the power to design option contract. The two sides negotiate through Stackelberg game to get their individual optimal strategy and implement the supply chain coordination.

\section{MODEL DESCRIPTION AND ASSUMPTIONS}

We assume that the supermarket has greater negotiating power to formulate the option contract, then the agricultural cooperative decides to purchase appropriate option quantity. With the coming of selling season, the supermarket carries out the policy after sufficient market demand information, but no more than the number agricultural cooperative has purchased. Cooperative should guarantee enough supply to supermarket, and the latter must compensate the former for the part which supermarket won't carry out, moreover it doesn't exceed the quantity cooperative has decided. Cooperative provides VMI service to supermarket, and information is shared between the parties.

\subsection{Assumptions}

1. To make it simple, we assume there are only one supermarket and one agricultural cooperative in the supply chain.

2. When the cooperative starts to supply products, the supermarket begins to sell it. Cooperative is competent to supply products timely and manage inventory of the whole chain, regardless of the quantity sold on supermarket's shelves.

3. The supermarket must take full account of the cooperative's interests to set up contract conditions, attracting cooperative to participate in actively, so as to prevent out-ofstock to the greatest extent. Otherwise it will undertake shortage cost.

4. Consumption is carried out uniformly.

\subsection{Notations}

D:Stochastic market demand of the item; $f(x)$ : probability density function of $\mathrm{D} ; \mathrm{F}(\mathrm{x})$ :distribution function of $\mathrm{D}$; $\mathrm{F}^{-1}(\mathrm{x})$ :inverse function of $\mathrm{F}(\mathrm{x})$; c: unit procurement cost of cooperative; h:unit inventory cost of cooperative; v:unit inventory salvage value; s:surplus stock; g:unit shortage cost of supermarket; w: unit wholesale price; p:unit retail price; Q:order quantity without contract; $\mathrm{C}_{0}$ : unit sales price of option, the price that cooperative pays for getting the rights to sell products in supermarket; $\mathrm{C}_{\mathrm{e}}$ : unit executed price of option, the price that supermarket pays for obtaining the products from cooperative; $Q_{0}$ :order quantity with contract; $r$ : unit compensation price; $\overline{\mathrm{I}}:$ the level of average inventory;

The above parameters should satisfy the following constraints:

1. $v \leq c+h \leq g \leq C_{e} \leq p$, the unit shortage cost is no less than the unit product $\operatorname{cost}(c+h)$, which making 
supermarket to take a full consideration on partner's interests; and the unit wholesale price is no less than the unit executed price of option in order to make supermarket to make a profit.

2. $C_{0} \leq r$, the purpose of this condition is to guarantee cooperative's profit.

3. $C_{e} \geq c+h+C_{0}$. the option executive price has to be higher than cost plus the option price.

4. $C_{e} \geq v+r$. the option executive price has to be higher than the salvage value of the product plus compensate price.

5. $v<w<p$, the wholesale price is less than the retail price but greater than the salvage value.

\section{VMI SUPPLY CHAIN MODEL WITHOUT CON- TRACT}

\subsection{Inventory Strategy}

In this section, we consider the situation without contract. The expected sales volume of supermarket is determined by the order quantity and market demand. The demand of market faces two different situations: sufficient and insufficient.

In the face of sufficient demand, namely $D<Q$, surplus stock of cooperative is given by $s=Q-d$, and the average inventory is $\frac{2 \mathrm{Q}-\mathrm{d}}{2}$. On the contrary, namely $\mathrm{d} \geq \mathrm{Q}$, supermarket is confronted with out-of-stock, the function of surplus stock of cooperative is $s=0$. So the average inventory is $\frac{1}{2} \mathrm{Q}$. The expectation of average inventory is expressed as

$E \bar{I}=\int_{0}^{Q}\left(\frac{2 Q-x}{2}\right) f(x) d_{x}+\int_{Q}^{\infty} \frac{Q}{2} f(x) d_{x} 9$

\subsection{Centralized Decision-making Model}

In the circumstances, supermarket and cooperative cooperate closely with each other, pursuing the profit maximization of supply chain. So under centralized decision making, supply chain can achieve the overall optimum.

The profit function of the supply chain under centralized decision is

$\Pi(\mathrm{Q})=\mathrm{p} \min [\mathrm{D}, \mathrm{Q}]+\mathrm{v}(\mathrm{Q}-\mathrm{D})^{+}-\mathrm{g}(\mathrm{D}-\mathrm{Q})^{+}-\mathrm{cQ}-\mathrm{h} \overline{\mathrm{I}}$

The expected profit of supply chain, i.e. ЕП, can be easily computed on the basis of (1).

$$
\begin{aligned}
& E \Pi=\left(p-v+\frac{h}{2}\right) \int_{0}^{Q} x f(x) d_{x}+\left(p+g-\frac{h}{2}\right) \int_{Q}^{\infty} Q f(x) d_{x}+ \\
& (v-h) \int_{0}^{Q} Q f(x) d_{x}-c Q-g \int_{Q}^{\infty} x f(x) d_{x}
\end{aligned}
$$

Then the first derivative and the second derivative of (3) be expressed as follows:

$$
\begin{aligned}
& \frac{\partial \mathrm{E} \Pi}{\partial \mathrm{Q}}=-\left(\mathrm{p}+\mathrm{g}-\mathrm{v}+\frac{\mathrm{h}}{2}\right) \mathrm{F}(\mathrm{Q})+\mathrm{p}+\mathrm{g}-\mathrm{c}-\frac{\mathrm{h}}{2} \\
& \frac{\partial^{2} \mathrm{E} \Pi}{\partial^{2} \mathrm{Q}}=-\left(\mathrm{p}+\mathrm{g}-\mathrm{v}+\frac{\mathrm{h}}{2}\right) \mathrm{f}(\mathrm{Q})
\end{aligned}
$$

Because there are two conditions: $\mathrm{v} \leq \mathrm{c}+\mathrm{h} \leq \mathrm{g} \leq \mathrm{p}$ and $\mathrm{p}+\mathrm{g}-\mathrm{v}+\frac{\mathrm{h}}{2}>0$, we find that: $\frac{\partial^{2} \mathrm{E} \Pi}{\partial^{2} \mathrm{Q}}=-(\mathrm{p}+\mathrm{g}-\mathrm{v}+$ $\left.\frac{\mathrm{h}}{2}\right) \mathrm{f}(\mathrm{Q})<0$. So the expected profit function of the supply chain is a convex function in $\mathrm{Q}$. We know that the optimal order quantity, i.e. $Q_{1}$, can be obtained by equating the first derivative of (3) to zero. So,

$F\left(Q_{1}\right)=\frac{p+g-c-\frac{h}{2}}{p+g-v+\frac{h}{2}}$

The optimal order quantity of centralized decision model is given by,

$Q_{1}=F^{-1}\left(\frac{p+g-c-\frac{h}{2}}{p+g-v+\frac{h}{2}}\right)$

\subsection{Decentralized Decision-making Model}

We consider both sides are independent in this case, maximizing individual interests, and taking no account of the others. Through Stackelberg game, supermarket as the leader can predict cooperative's decision. We use backward induction to solve this problem.

\subsubsection{Decision-making Model of Cooperative}

The profit function of the cooperative under decentralized decision is:

$$
\Pi_{\mathrm{c}}(\mathrm{Q})=\mathrm{w} \min [\mathrm{D}, \mathrm{Q}]+\mathrm{v}(\mathrm{Q}-\mathrm{D})^{+}-\mathrm{cQ}-\mathrm{h} \overline{\mathrm{I}}
$$

The expected profit of $\Pi_{h}(Q)$ is given by

$$
\begin{aligned}
& E \Pi_{c}=\left(w-v+\frac{h}{2}\right) \int_{0}^{Q} x f(x) d_{x}+\left(w-\frac{h}{2}\right) \int_{Q}^{\infty} Q f(x) d_{x}+ \\
& (v-h) \int_{0}^{Q} Q f(x) d_{x}-c Q
\end{aligned}
$$

We also compute the first derivative and the second derivative of formula (9). The functions are:

$$
\begin{aligned}
& \frac{\partial E \Pi_{\mathrm{c}}}{\partial \mathrm{Q}}=-\left(\mathrm{w}-\mathrm{v}+\frac{\mathrm{h}}{2}\right) \mathrm{F}(\mathrm{Q})+\mathrm{w}-\mathrm{c}-\frac{\mathrm{h}}{2} \\
& \frac{\partial^{2} \mathrm{E} \Pi_{\mathrm{c}}}{\partial^{2} \mathrm{Q}}=-\left(\mathrm{w}-\mathrm{v}+\frac{\mathrm{h}}{2}\right) \mathrm{f}(\mathrm{Q})
\end{aligned}
$$

In a similar way, due to the constraint: $\mathrm{v}<\mathrm{w}$, we know that: $\frac{\partial^{2} \mathrm{Ec}}{\partial^{2} \mathrm{Q}}=-\left(\mathrm{w}-\mathrm{v}+\frac{\mathrm{h}}{2}\right) \mathrm{f}(\mathrm{Q})<0$. Then the expected profit function of the cooperative is a convex function in $Q$. Equating the first derivative of (9) to zero, we can get the optimal order quantity of cooperative in decentralized decision model. That is:

$\mathrm{Q}_{2}=\mathrm{F}^{-1}\left(\frac{\mathrm{w}-\mathrm{c}-\frac{\mathrm{h}}{2}}{\mathrm{w}-\mathrm{v}+\frac{\mathrm{h}}{2}}\right)$

\subsubsection{Decision-making Model of Supermarket}

The profit function of the supermarket under decentralized decision is expressed as

$\Pi_{s}(Q)=(p-w) \min [D, Q]-g(D-Q)^{+}$ 
The function of the expected profit of $\Pi_{s}(Q)$ is

$\mathrm{E} \Pi_{\mathrm{s}}=$

$-(\mathrm{p}-\mathrm{w}) \int_{0}^{\mathrm{Q}} \mathrm{F}(\mathrm{x}) \mathrm{d}_{\mathrm{x}}+$

$(\mathrm{p}-\mathrm{w}+\mathrm{g}) \mathrm{Q}-\mathrm{g} \int_{\mathrm{Q}}^{\infty} \mathrm{xf}(\mathrm{x}) \mathrm{d}_{\mathrm{x}}-\mathrm{gQF}(\mathrm{Q})$

Substituting $Q_{2}$ into (8) the expected profits of supermarket can now be expressed as

$\mathrm{E} \Pi_{\mathrm{s}}=$

$-(\mathrm{p}-\mathrm{w}) \int_{0}^{\mathrm{Q}_{2}} \mathrm{~F}(\mathrm{x}) \mathrm{d}_{\mathrm{x}}+(\mathrm{p}-\mathrm{w}+\mathrm{g}) \mathrm{Q}_{2}-\mathrm{g} \int_{\mathrm{Q}_{2}}^{\infty} \mathrm{xf}(\mathrm{x}) \mathrm{d}_{\mathrm{x}}-$ $\mathrm{gQ}_{2} \mathrm{~F}\left(\mathrm{Q}_{2}\right)$

We can distinctly show that (9) is a function in w. The next step is to calculate the most appropriate value of $\mathrm{w}$, which we use $w^{\prime}$ to replace, to achieve supermarket's maximum profit goal. Then, the function of the optimal supply quantity of cooperative in decentralized decision model turns into:

$\mathrm{Q}_{2}=\mathrm{F}^{-1}\left(\frac{\mathrm{w}^{\prime}-\mathrm{c}-\frac{\mathrm{h}}{2}}{\mathrm{w}^{\prime}-\mathrm{v}+\frac{\mathrm{h}}{2}}\right)$

We suppose that $\mathrm{x} \sim \mathrm{U}[0,2000], \mathrm{p}=30, \mathrm{c}=4, \mathrm{~h}=2, \mathrm{v}=$ $4, g=10$. According to (3), we obtain the value of the optimal order quantity of centralized decision model, namely $\mathrm{Q}_{1}=1891.89$, and the value of expected profit of supply chain, i.e. $\mathrm{E \Pi}=23108.11$.

Because (9) is a function of $w$,we calculate the value of $\mathrm{w}^{\prime}$ to maximize $\mathrm{E} \Pi_{\mathrm{s}}$. When $\mathrm{w}^{\prime}$ equals to $9.5, \mathrm{E} \Pi_{\mathrm{s}}$ has the maximum value. Furthermore, we count values as: $\mathrm{Q}_{2}=1384.62, \mathrm{E} \Pi_{\mathrm{s}}=17612.43, \mathrm{E} \Pi_{\mathrm{c}}=4073.96$. So the overall expected profit of supply chain can be known by the function, i.e. $\mathrm{E} \Pi^{\prime}=\mathrm{E} \Pi_{\mathrm{c}}+\mathrm{E} \Pi_{\mathrm{s}}=21686.39$. Analyzing the above data, we see clearly that $1891.89>1384.6$, namely $\mathrm{Q}_{1}>\mathrm{Q}_{2}$, and 23108.11 > 21686.39, namely EП $>E \Pi^{\prime}$. In other words, the levels of decentralized decision model are less than the ones of centralized decision model, which indicates that there's double marginalization in supply chain, and the supply chain need to be coordinated.

\section{VMI SUPPLY CHAIN MODEL WITH OPTION CONTRACT}

In this case, supermarket decides the value of $\mathrm{C}_{0}$ and $\mathrm{C}_{\mathrm{e}}$ firstly, then cooperative gives the value of $Q_{0}$. In the same way, we use backward induction to solve it.

\subsection{Inventory Strategy}

The inference procedure of inventory strategy is the same with the model without contract. So we imitate the above function to show the average inventory expectation as follows,

$E \bar{I}=\int_{0}^{Q_{0}}\left(\frac{2 Q_{0}-x}{2}\right) f(x) d_{x}+\int_{Q_{0}}^{\infty} \frac{Q_{0}}{2} f(x) d_{x}$

\subsection{Decision-making Model of Cooperative}

The profit function of the cooperative with option contract is:

$\Pi_{\mathrm{c}}^{\prime}\left(\mathrm{Q}_{0}\right)=\mathrm{C}_{\mathrm{e}} \min \left[\mathrm{D}, \mathrm{Q}_{0}\right]+\mathrm{v}\left(\mathrm{Q}_{0}-\mathrm{D}\right)^{+}+\mathrm{r}\left(\mathrm{Q}_{0}-\mathrm{D}\right)^{+}-$
$\mathrm{C}_{0} \mathrm{Q}_{0}-\mathrm{cQ}_{0}-\mathrm{hE} \overline{\mathrm{I}}$

The function of the expected profit of $\Pi_{c}^{\prime}\left(Q_{0}\right)$ is

$\mathrm{E}_{\mathrm{c}}^{\prime}=$

$\left(C_{e}-v-r+\frac{h}{2}\right) \int_{0}^{Q_{0}} x f(x) d_{x}+\left(C_{e}-\frac{h}{2}\right) \int_{Q_{0}}^{\infty} Q_{0} f(x) d_{x}+$

$(\mathrm{v}+\mathrm{r}-\mathrm{h}) \int_{0}^{\mathrm{Q}_{0}} \mathrm{Q}_{0} \mathrm{f}(\mathrm{x}) \mathrm{d}_{\mathrm{x}}-\left(\mathrm{c}+\mathrm{C}_{0}\right) \mathrm{Q}_{0}$

The first derivative and the second derivative of (19) are showed below,

$\frac{\partial \mathrm{E}_{\mathrm{c}}^{\prime}}{\partial \mathrm{Q}_{0}}=-\left(\mathrm{C}_{\mathrm{e}}-\mathrm{v}-\mathrm{r}+\frac{\mathrm{h}}{2}\right) \mathrm{F}\left(\mathrm{Q}_{0}\right)+\mathrm{C}_{\mathrm{e}}-\mathrm{C}_{0}-\mathrm{c}-\frac{\mathrm{h}}{2}$

$\frac{\partial^{2} E_{C}^{\prime}}{\partial^{2} Q_{0}}=-\left(C_{e}-v-r+\frac{h}{2}\right) f\left(Q_{0}\right)$

Due to the condition: $\mathrm{C}_{\mathrm{e}} \geq \mathrm{v}+\mathrm{r}$, we have a conclusion that: $\frac{\partial^{2} E_{c}^{\prime}}{\partial^{2} Q_{0}}=-\left(C_{e}-v-r+\frac{h}{2}\right) f\left(Q_{0}\right)<0$. So the expected profit function of the cooperative is a convex function in $Q_{0}$. Equating the first derivative of (19) to zero, we can get the optimal order quantity of cooperative with option contract. Under this circumstances, cooperative realizes maximum benefits, and the value of $Q_{0}^{*}$ is unique.

$F\left(Q_{0}^{*}\right)=\frac{C_{e}-C_{0}-c-\frac{h}{2}}{C_{e}-v-r+\frac{h}{2}}$
$Q_{0}^{*}=F^{-1}\left(\frac{C_{e}-C_{0}-c-\frac{h}{2}}{C_{e}-v-r+\frac{h}{2}}\right)$

\subsection{Decision-making Model of Supermarket}

The profit function of the supermarket with option contract is:

$$
\begin{aligned}
& \Pi_{\mathrm{s}}^{\prime}\left(\mathrm{Q}_{0}\right)=\left(\mathrm{p}-\mathrm{C}_{\mathrm{e}}\right) \min \left[\mathrm{D}, \mathrm{Q}_{0}\right]-\mathrm{g}\left(\mathrm{D}-\mathrm{Q}_{0}\right)^{+}- \\
& \mathrm{r}\left(\mathrm{Q}_{0}-\mathrm{D}\right)^{+}+\mathrm{C}_{0} \mathrm{Q}_{0}
\end{aligned}
$$

Similarly, we can know the function of the expected profit of $\Pi_{\mathrm{s}}^{\prime}\left(\mathrm{Q}_{0}\right)$.

$\mathrm{E}_{\mathrm{s}}^{\prime}=$

$\left(p-C_{e}+r\right) \int_{0}^{Q_{0}} x f(x) d_{x}+\left(p-C_{e}+g\right) \int_{Q_{0}}^{\infty} Q_{0} f(x) d_{x}-$

$r \int_{0}^{Q_{0}} Q_{0} f(x) d_{x}-g \int_{Q_{0}}^{\infty} x f(x) d_{x}+C_{0} Q_{0}$

Putting $\mathrm{Q}_{0}^{*}$ into the $(25)$, it becomes $\mathrm{E}_{\mathrm{S}}^{\prime}\left(\mathrm{Q}_{0}^{*}\right)$. If the expected profit of supply chain reaches the level of centralized decision-making model.

Then,

$\frac{\mathrm{C}_{\mathrm{e}}-\mathrm{C}_{0}-\mathrm{c}-\frac{\mathrm{h}}{2}}{\mathrm{C}_{\mathrm{e}}-\mathrm{v}-\mathrm{r}+\frac{\mathrm{h}}{2}}=\frac{\mathrm{p}+\mathrm{g}-\mathrm{c}-\frac{\mathrm{h}}{2}}{\mathrm{p}+\mathrm{g}-\mathrm{v}+\frac{\mathrm{h}}{2}}$

That is, 
Table 1. Expected profit of the cooperatives and supermarkets with different values of $C_{0}$ and $C_{e}$.

\begin{tabular}{ccccccc}
\hline $\mathbf{C}_{\mathbf{0}}$ & $\mathbf{2 . 2}$ & $\mathbf{2 . 4}$ & $\mathbf{2 . 6}$ & $\mathbf{2 . 8}$ & $\mathbf{3 . 0}$ & $\mathbf{3 . 2}$ \\
\hline $\mathbf{C}_{\mathbf{e}}$ & 10.7 & 14.4 & 18.1 & 21.8 & 25.5 & 29.2 \\
$\mathbf{E}_{\mathbf{c}}^{\prime}$ & 3310.81 & 6621.62 & 9932.43 & 13243.24 & 16554.05 & 19864.86 \\
$\mathbf{E}_{\mathbf{s}}^{\prime}$ & 19797.30 & 16486.49 & 13175.68 & 9864.86 & 6554.05 & 3243.24 \\
$\mathbf{E}^{\prime}$ & 23108.11 & 23108.11 & 23108.11 & 23108.10 & 23108.10 & 23108.10 \\
\hline
\end{tabular}

$$
\mathrm{C}_{0}=\mathrm{C}_{\mathrm{e}}-\mathrm{c}-\frac{\mathrm{h}}{2}-\frac{\mathrm{p}+\mathrm{g}-\mathrm{c}-\frac{\mathrm{h}}{2}}{\mathrm{p}+\mathrm{g}-\mathrm{v}+\frac{\mathrm{h}}{2}}\left(\mathrm{C}_{\mathrm{e}}-\mathrm{v}-\mathrm{r}+\frac{\mathrm{h}}{2}\right)
$$

It shows that, $\mathrm{C}_{0}$ has linear relationship with $\mathrm{C}_{\mathrm{e}}$. If other parameters are determined in a reasonable range, $\mathrm{C}_{0}$ and $\mathrm{C}_{\mathrm{e}}$ are one-to-one correspondence. With option contract, cooperative and supermarket can not only realize the overall optimal level of centralized decision, but also achieving a reasonable distribution of profits between them based on different values of $\mathrm{C}_{0}$ and $\mathrm{C}_{\mathrm{e}}$.

We continue to assume the value of $r$, i.e. $r=4$, then (12) is equivalent to the function: $C_{e}=18.5 C_{0}-30$. And the overall expected profit of supply chain is known as $E^{\prime}$, namely the function: $E^{\prime}=E_{c}^{\prime}+E_{s}^{\prime}$. The expected profit of supermarket, cooperative and the supply chain change with different values of $\mathrm{C}_{0}$ and $\mathrm{C}_{\mathrm{e}}$ as follows:

Table 1 indicates that when $C_{0}$ increases, the value of $C_{e}$ and the expected profit of cooperative add too, in contrast, supermarket's expected profit reduces. In order to have distribution rights in the supermarket, the more money cooperative invests, the greater amount of feedback it will get from supermarket. The most important reason for supermarket choosing the option contract is to guarantee the quality of agricultural products by cooperating with professional cooperative. At the same time, the members of the chain develop the win-win relationship.

\section{CONCLUSION}

As a kind of effective supply chain inventory management model, VMI provides a new opportunity for agricultural products supply chain. In this paper, we prove that option contract can coordinate the supply chain, achieving a reasonable distribution of profits between agricultural cooperative and supermarket. We assume that supermarket is the leader, and cooperative is the follower, which accords with the reality of our country.

In supply chain connecting agriculture with supermarkets, supermarket can choose professional cooperative guaranteeing high quality of products, realizing food tractability for terminal consumer. On the other hand, cooperative can guides farmers to plant reasonably in case of homogeneous competition and the phenomenon that low grain price hurts the farmers.
But this paper considers only two-echelon supply chains with agricultural cooperative and supermarket, without farmers who are important members of the chain. So we will continue to focus on three-echelon supply chains model.

\section{CONFLICT OF INTEREST}

The authors confirm that this article content has no conflict of interest.

\section{ACKNOWLEDGEMENTS}

Declared none.

\section{REFERENCES}

[1] D. Zhao, and X. Lv, "An overview and comment on theoretical development of vendor-managed inventory," Journal of Beijing Jiaotong University (Social Sciences Edition), vol. 11, no. 1, pp. 41-47, 2012

[2] S.M. Disney, and D.R. Towill, "The effect of vendor managed inventory (VMI) dynamics on the Bullwhip Effect in supply chains," International Journal of Production Economics, vol. 85, pp. 199-215, 2003.

[3] L. Liu, and J. Yuan, "Inventory and dispatch models in vmi systems," Chinese Journal of Management Science, vol. 11, no. 5, pp. 31-36, 2003

[4] H. Tang, R. Yi, and W. Zhu, "Analyses on the impact of game structure to the performance of supply chain of VMI," Chinese Journal of Management Science, vol. 13, no. 5, pp. 71-78, 2005.

[5] L. Liang, X. Pu, and L. Ling, "The probability analysis research of two-echelon VMI supply chain," Operations Research and Management Science, vol. 15, no. 4, pp. 33-37, 2006.

[6] B.C. Bichescu, and M.J. Fry, "Vendor-managed inventory and the effect of channel power," OR Spectrum, vol. 31, pp. 195-228, 2009

[7] Y. Yu, G.Q. Huang, and L. Liang, "Stackelberg game-theoretic model for optimizing advertising, pricing and inventory policies in vendor managed inventory (VMI) production supply chains," Computers \& Industrial Engineering, vol. 57, pp. 368-382, 2009.

[8] S.P. Sarmaha, D. Acharyaa, and S.K. Goyal, "Coordination and profit sharing between a manufacturer" and a buyer with target profit under credit option," European Journal of Operational Research, vol. 182, pp. 1469-1478, 2007.

[9] S. Sarmah, D. Acharya, and S. Goyal, "Coordination of a singlemanufacturer/ multi-buyer supply chain with credit option," International Journal of Production Economics, vol. 111, no. 2, pp. 676-685, 2008.

[10] A.G. Padilla, and T. Mishina, "Supply contract with options," International Journal of Production Economics, vol. 122, pp. 312318, 2009.

[11] S.K. Chaharsooghi, and J. Heydari, "Supply chain coordination for the joint determination of order quantity and reorder point using credit option," European Journal of Operational Research, vol. 204, pp. 86-95, 2010.

[12] Y. Zhao, S. Wang, T.C.E. Cheng, X.Yang, and Z. Huang, "Coordination of supply chains by option contracts: A cooperative game 
theory approach," European Journal of Operational Research, vol. 207, pp. 668-675, 2010.

[13] J. Wu, and J. Liu, "Option contracts of supply chain coordination in a VMI system through under uncertainty," Systems Engineering, vol. 29, no. 3, pp. 1-8, 2011.

[14] L. Li, and T. Fan, "Coordination by option contract in two-echelon supply chain with uncertainty," Journal of Systems Engineering, vol. 27 , no. 6 , pp. 812-822, 2012.

[15] R. Du, A.V. Banerjee, and S. Kim, "Coordination of two-echelon supply chains using wholesale price discount and credit option," International Journal of Production Economics, vol. 143, pp. 327334, 2013.

[16] H. Cai, H. Cai, and D. Zhang, "Fuzzy option contract with jointed advertising investment sharing in a retailer-led supply chain," Journal of Systems Engineering, vol. 26, no. 3, pp. 323-329, 2011.

[17] H. Cai, and X. Zhang, "Study on option contract with supplier's innovation investment or retailer's innovation investment in a retailer-led supply chain," Chinese Journal of Management Science, vol. 20, pp. 608-614, 2012.
[18] X. Zhao, and F. Wu, "Coordination of agri-food chain with revenue-sharing contract under stochastic output and demand," Chinese Journal of Management Science, vol. 17, no. 5, pp. 88-95, 2009.

[19] P. Moustiera, P.T.G. Tamb, D.T. Anhc, V.T. Binhd, and N.T.T. Loce, "The role of farmer organizations in supplying supermarkets with quality food in Vietnam," Food Policy, vol. 35, pp. 69-78, 2010.

[20] Y. Li, W. Yang, K. Zhang, and D. Hu, "Research on factors influencing professional cooperative to take part in the model of connecting agriculture with supermarkets," Journal of Agrotechnical Economics, vol. 5, pp. 65-71, 2011.

[21] L. Liu, Z. Qiao, and C. Liu, "A cooperative game in the model of connecting agriculture with supermarkets," Journal of Industrial Engineering/Engineering Management, vol. 4, pp. 100-106, 2012.

[22] F. Ye, Q. Lin, and Y. Li, "Supply chain coordination for "company + farmer" contract-farming with CVaR criterion," Systems Engineering-Theory \& Practice, vol. 31, no. 3, pp. 450-460, 2011.

Received: September 16, 2014

Revised: December 23, 2014

Accepted: December 31, 2014

(C) You and Zhao; Licensee Bentham Open.

This is an open access article licensed under the terms of the Creative Commons Attribution Non-Commercial License (http://creativecommons.org/licenses/by-nc/3.0/) which permits unrestricted, non-commercial use, distribution and reproduction in any medium, provided the work is properly cited. 